\title{
Comparative Evaluation of Laparoscopic with Open Appendectomy among Patients of Appendectomy - A Prospective Study
}

\author{
Burra Viswa Chaitanya ${ }^{1}$, Rama Chandra Mohan Mallapragada ${ }^{2}$ \\ ${ }^{1}$ Assistant Professor, department of General Surgery, ${ }^{2}$ Assistant Professor, Department of General Surgery, NRI General \\ Hospital, Visakhapatnam, Andhra Pradesh, India
}

Corresponding author: Dr Rama Chandra Mohan. M, Assistant Professor, Department of General Surgery, NRI General Hospital, Visakhapatnam, Andhra Pradesh, India

DOI: http://dx.doi.org/10.21276/ijcmsr.2019.4.3.4

How to cite this article: Burra Viswa Chaitanya, Rama Chandra Mohan Mallapragada. Comparative evaluation of laparoscopic with open appendectomy among patients of appendectomy - a prospective study. International Journal of Contemporary Medicine Surgery and Radiology. 2019;4(3):C18-C22.

\section{A B S T R A C T}

Introduction: Appendectomy is the treatment of choice for acute appendicitis and is by far the most commonly performed emergency abdominal operation. It has been found that open appendectomy is also a safe and effective operation for acute appendicitis with low morbidity, but found to be associated with potential disadvantages like post-operative pain, wound sepsis and complications like intestinal obstruction which may delay recovery. With the emergence of laparoscopic technique, it has become a good option for both diagnosis and treatment of acute appendicitis. Therefore, the aim of the current study was to compare the laparoscopic with open appendectomy among patients of appendicitis.

Material and Methods: The present study was a prospective study with total 140 patients admitted with clinical diagnosis of acute or recurrent appendicitis. The patients with severe medical disease (, chronic medical, hemodynamic instability or psychiatric illness, cirrhosis, coagulation disorders) requiring intensive care and pregnant women were excluded from the study. They were divided into two groups: open appendectomy (OA) group with 70 patients in each) and laparoscopic appendectomy (LA) group (70 patients in each). OA was performed through standard Mc Burney incision. A standard 3-port technique was used in this study for the laparoscopic procedure.

Results: It is found that laparoscopic appendectomy is as safe and effective as the open procedure. The pain score was reduced in laparoscopic which is $3.4 \pm 1.8$ and in open $4.2 \pm 1.4$. This difference was found to be statistically significant at $p$ value of 0.05 . The duration of analgesics was also reduced in laparoscopic with mean value of $4.81 \pm 3.6$ and $10.32 \pm 4.2$ and this difference was found to be statistically significant at $p$ value of 0.05 .

Conclusion: The laparoscopic procedure is a safe and efficient in appendectomy with clinically beneficial advantages over open method.s

Keywords: Laparoscopic appendectomy, open appendectomy, appendicitis, prospective

\section{INTRODUCTION}

In the sixteenth century, appendicitis was considered as a disease entity and was known as perityphlitis. In 1889, these clinical findings were noted first by McBurney. Useful surgical technique which has been proved is minimal access surgery. For various indications new standards have been made. In $21^{\text {st }}$ century, the greater consideration is given to patient's comfort. This choice is because of the acquisition of recent technology and skills for the better mode of surgery. ${ }^{1}$ The most common cause of surgical abdomen is appendicitis affecting all the age groups. The maximum incidence is documented to be about $7-10 \%$ of the general population in the second and third decades of life. Appendectomy is the operation which is most commonly performed by the general surgeons. The diagnosis of acute appendicitis is often difficult, and challenging. An accepted negative appendectomy rate for presumed appendicitis ranges from $15 \%$ to $20 \%$, even higher in women of childbearing age ranging from $20 \%$ to $30 \% .^{2,3}$

The Laparoscopic appendectomy was first performed by Semm K, German Gynaecologist. It has gained acceptance with the technological advances of the past two to three decades as a diagnostic and treatment method for acute appendicitis. From that time, this procedure has been used widely. In spite of its wide acceptance, there remains a continuing debate in the literature related to the most appropriate way of removing the inflamed appendix. ${ }^{4}$

This method is regarded as safe and effective for suspected appendicitis. In recent years, it has gained attention is regarded as most widely used procedures throughout the world. However, it was still not considered as gold standard for acute appendicitis as laparoscopic cholecystectomy has become for acute cholecystitis. It was due to the emergency nature of disease often operated by junior staff in odd hours 
when laparoscopic equipment, trained staff and supervision may not be available in all hospitals. ${ }^{5,6}$

It has been found from the literature that open appendectomy is regarded as the gold standard for treating patients with acute appendicitis. It has been noted that this is due to the minimal surgical trauma through laparoscopic approach which resulted in significant shorter hospital stay, less postoperative pain and faster return to daily activities in several settings related with gastrointestinal surgery.

However, several retrospective studies, randomized trials and meta-analysis have compared laparoscopic with open appendectomy and showed conflicting results. Various studies have showed better outcomes clinically with the help of laparoscopic approach., ${ }^{7,8}$ Some authors consider emergency laparoscopy as a promising tool for the treatment of abdominal emergencies which is able to decrease the cost and invasiveness by increasing the patient's comfort and outcomes. Many studies have shown promising results with fewer wound complications in laparoscopic appendectomy and results in a faster return to daily activities.

Various authors have challenged these clinical findings by various authors who supported no significant difference in the outcome between the two procedures, and moreover noted higher costs with laparoscopic appendectomy. This modern time of laparoscopic surgery has revealed remarkable changes in surgical diseases. General surgeons have changed the trend towards minimally invasive surgery to analyse every operations possible to convert into laparoscopic techniques. ${ }^{9,10}$ Hence, the aim of the present study was to compare the laparoscopic with open appendectomy among patients of appendicitis.

\section{MATERIAL AND METHODS}

The present study was a prospective study with patients admitted to a surgical ward from a period between September 2018 and September 2019. The protocol of the study was approved by the Institutional Review Board and the Ethical Committee of the college. Written informed consent from patient and their relatives was obtained prior to the beginning of the study.

Those with clinical diagnosis of acute or recurrent appendicitis were included in the study. Those with severe medical diseases (hemodynamic instability, chronic medical or psychiatric illness, cirrhosis, coagulation disorders) with intensive care were excluded from this study. According to the preference and experience of the surgical team on duty, the decision about the type of the operation was made. Clinically, the diagnosis was made with history (right iliac fossa or periumbilical pain, nausea/vomiting), physical examination (tenderness or guarding in right iliac fossa).

Total 140 patients that met the inclusion criteria and their clinical data and hospital costs were included in the study. The patients were divided into two groups: open appendectomy group (70 patients each) and laparoscopic appendectomy group (70 patients each). The data was collected related to demographic details, co-morbidities, initial laboratory findings, operation time, intraoperative findings (acute, gangrenous or perforated appendix), time to soft diet, postoperative hospital stay, amount of analgesics and postoperative complications.

Imaging studies such as abdominal ultrasound or CT were performed in patients where a clinical diagnosis is not possible. As part of the protocol, both the groups of patients were given a prophylactic dose of third-generation cephalosporin and metronidazole at induction of the general anaesthesia. Open Appendectomy was done with the help of standard Mc Burney incision. After the incision, peritoneum was accessed and opened to deliver the appendix, which was removed in the usual manner.

A standard 3-port technique was used for laparoscopic group. Pneumoperitoneum was generated by a continuous pressure of $12-14 \mathrm{mmHg}$ of carbon dioxide via a verres canula, positioned in infraumbilical site. The patient was placed in a trendelenburg position, with a slight rotation to the left. The abdominal cavity was inspected in order to exclude other intrabdominal or pelvic pathology.

Until they were recovered fully from anaesthesia, the patients were not provided with oral feed and had their bowel sounds returned when clear fluids were started. When the patients tolerated the liquid diet and had passed flatus soft diet was introduced. Patients were discharged once they were able to take regular diet and had good control of pain.

Wound infection is defined as pus discharge which requires surgical drainage. Intra-abdominal abscess is defined as a fluid collection diagnosed at Ultrasonography or computed tomography which contained pus at ultrasonographically guided aspiration. Various parameters were recorded during follow up in comparison between two procedures, using a visual analogue pain scale, post-operative pain was measured and duration of analgesic was recorded in number of days. Various post-operative complications like vomiting, ileus, abdominal abscess and wound infection were also recorded. Patients in both study groups were discharged as soon as possible and duration of stay after surgery and duration of analgesics used after surgery in number of days was also noted.

\section{STATISTICAL ANALYSIS}

The data collected was recorded in Microsoft excel sheet which was analyzed with the help of SPSS software version 21. The inferential statistics was used to categorize data with the help of chi-square test. The parametric and nonparametric data was analyzed with the help of t-test and Mann-whitney ' $U$ ' test and data was presented as mean and standard deviation. A p- value of 0.05 was considered to be statistically significant.

\section{RESULTS}

In the present study, Table no. 1 and 2 shows that out of 140 patients, $54.2 \%$ were males and $45.7 \%$ were females in open appendectomy and about $42.8 \%$ males and $57.1 \%$ were

\begin{tabular}{|l|c|c|c|c|}
\hline Treatment Procedure & \multicolumn{2}{|c|}{ Open } & \multicolumn{2}{c|}{ Laparoscopic } \\
\hline Gender & No. & $\%$ & No. & $\%$ \\
\hline Male & 38 & 54.2 & 30 & 42.8 \\
\hline Female & 32 & 45.7 & 40 & 57.1 \\
\hline \multicolumn{3}{|c|}{ Table-1: Shows the distribution of data based on gender } \\
among the two groups \\
\hline
\end{tabular}


females. About 48.5\% were from the age group 10-20 years and $40 \%$ from the age group $21-30$ years with $5.7 \%$ from the age group 31-40 years and $41-50$ years in the treatment procedure of open appendectomy whereas in laparoscopic $45.7 \%$ were from the age group 10-20 years followed by

\begin{tabular}{|l|c|c|c|c|}
\hline Treatment Procedure & \multicolumn{2}{|c|}{ Open } & \multicolumn{2}{c|}{ Laparoscopic } \\
\hline Age & No. & $\%$ & No. & $\%$ \\
\hline $10-20$ years & 34 & 48.5 & 32 & 45.7 \\
\hline 21-30 years & 28 & 40 & 30 & 42.8 \\
\hline $31-40$ years & 4 & 5.7 & 2 & 2.8 \\
\hline 41-50 years & 4 & 5.7 & 6 & 8.5 \\
\hline
\end{tabular}

Table-2: Shows the distribution of data based on age among the two groups

\begin{tabular}{|l|c|c|c|c|}
\hline Treatment Procedure & \multicolumn{2}{|c|}{ Open } & \multicolumn{2}{c|}{ Laparoscopic } \\
\hline Presenting Symptoms & No. & $\%$ & No. & $\%$ \\
\hline Abdominal Pain & 70 & 100 & 70 & 100 \\
\hline Nausea/Vomiting & 56 & 80 & 64 & 91.4 \\
\hline Fever & 30 & 42.8 & 22 & 31.4 \\
\hline $\begin{array}{c}\text { Table-3: Shows the distribution of data based on presenting } \\
\text { symptoms pre-operatively among the two groups }\end{array}$ \\
\hline
\end{tabular}

\begin{tabular}{|l|c|c|c|c|}
\hline Treatment Procedure & \multicolumn{2}{|c|}{ Open } & \multicolumn{2}{c|}{ Laparoscopic } \\
\hline Past History & No. & $\%$ & No. & $\%$ \\
\hline Episode of Pain & 20 & $28.5 \%$ & 24 & $34.2 \%$ \\
\hline Table-4: Shows the distribution of data based on past history \\
among the two groups \\
\hline
\end{tabular}

\begin{tabular}{|l|c|c|c|c|}
\hline Treatment Procedure & \multicolumn{2}{|c|}{ Open } & Laparoscopic \\
\hline Findings & No. & $\%$ & No. & $\%$ \\
\hline Tenderness & 70 & 100 & 70 & 100 \\
\hline Present & 0 & 0 & 0 & 0 \\
\hline Absent & 58 & 82.8 & 62 & 88.5 \\
\hline Guarding/ Rigidity & 12 & 17.14 & 8 & 11.4 \\
\hline Present & No. & $\%$ & No. & $\%$ \\
\hline Absent & 8 & 11.4 & 18 & 25.7 \\
\hline Report & 62 & 88.57 & 52 & 74.2 \\
\hline Normal & $\begin{array}{l}\text { Abnormal Pathology Needed } \\
\text { Table-5: Shows the distribution of data based on tenderness, } \\
\text { rigidity and pathology report among the two groups }\end{array}$ \\
\hline
\end{tabular}

\begin{tabular}{|l|c|c|c|c|}
\hline Treatment Procedure & \multicolumn{2}{|c|}{ Open } & \multicolumn{2}{|c|}{ Laparoscopic } \\
\hline Mean & \multicolumn{2}{|c|}{14220} & \multicolumn{2}{|c|}{13940} \\
\hline SD & \multicolumn{2}{|c|}{ \pm 4562} & \multicolumn{2}{|c|}{ \pm 4876} \\
\hline Differential count with shift to left & No. & $\%$ & No. & $\%$ \\
\hline Present & 64 & 91.4 & 58 & 82.8 \\
\hline Absent & 6 & 8.5 & 12 & 17.14 \\
\hline
\end{tabular}

Table-6: Shows the distribution of data based on differential count among the two groups
$42.8 \%$ from $21-30$ years with $8.5 \%$ from the age groups 31 40 years and $2.8 \%$ from the age group $41-50$ years.

It is found from the Table no. 3 and 4 that the most common presenting symptoms were abdominal pain in open and laparoscopic type of procedure (100\%) followed by nausea, vomiting (80\%) in open and $91.4 \%$ in laparoscopic

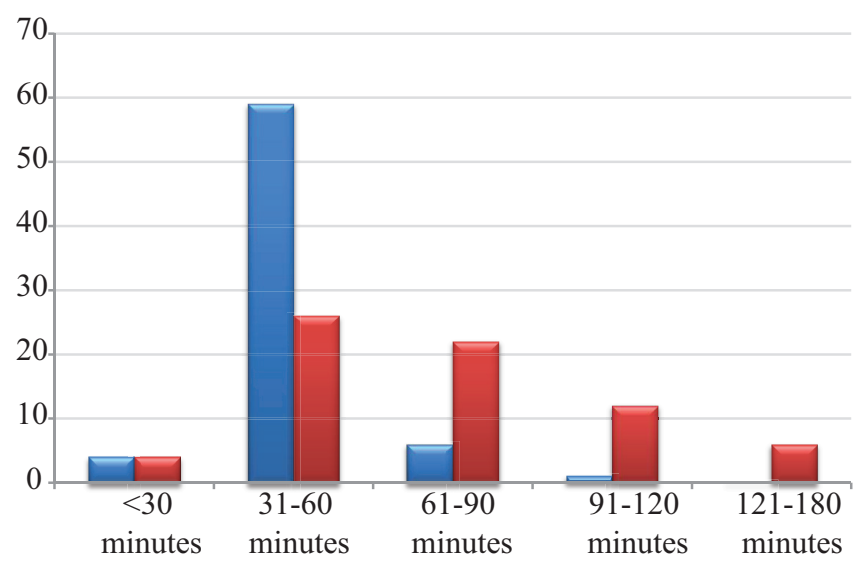

Graph-1: shows the distribution of data based on duration of surgery among the two groups

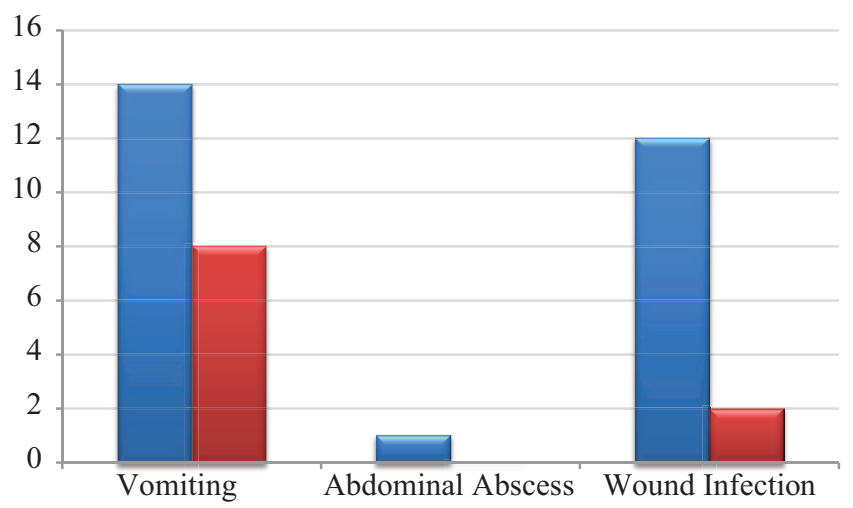

Graph-2: shows the distribution of data based on postoperative complications among the two groups

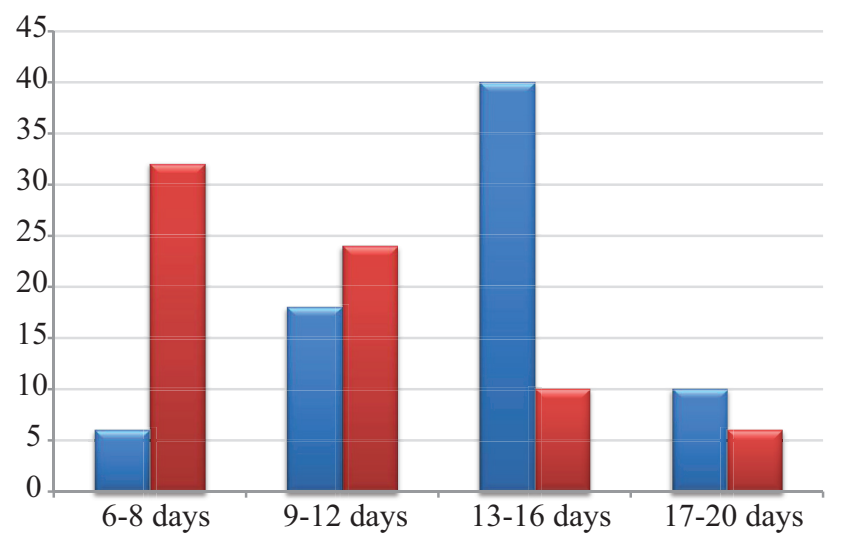

Graph-3: shows the distribution of data based on days of recovery after surgery among the two groups

\begin{tabular}{|l|c|c|c|c|}
\hline Treatment Procedure & Open & Laparoscopic & t-value & p-value \\
\hline Pain score(0-4) & $4.2 \pm 1.4$ & $3.4 \pm 1.8$ & 7.26 & $<0.05$ \\
\hline Duration of Analgesics used & $10.32 \pm 4.2$ & $4.81 \pm 3.6$ & 9.42 & $<0.05$ \\
\hline \multicolumn{2}{|r|}{ Table-7: Shows the distribution of data based on pain score and duration of analgesics among the two groups } \\
\hline
\end{tabular}




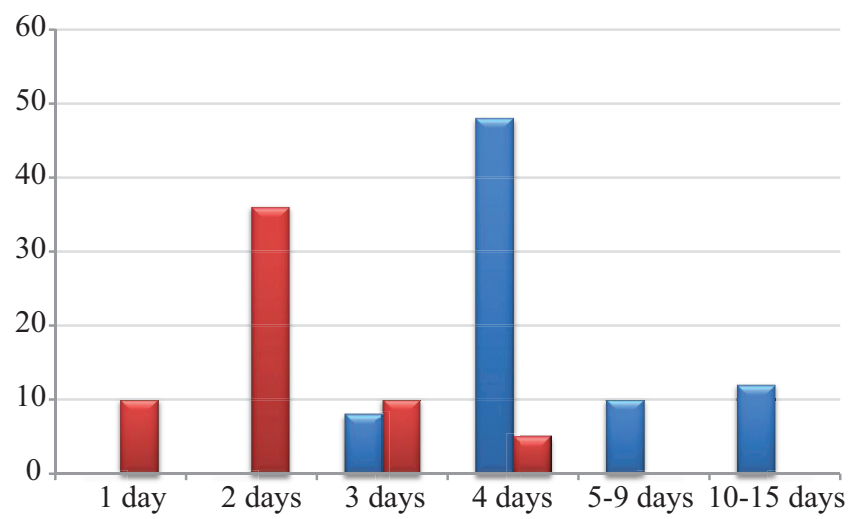

Graph-4: shows the distribution of data based on duration of hospital stay after surgery among the two groups

appendectomy with fever in $42.8 \%$ of patients in open and $31.4 \%$ in laparoscopic procedures. Patients with past history with episodes of pain is more (34.2\%) seen in laparoscopic than open $(28.5 \%)$.

It is seen that tenderness was maximum present in both open and laparoscopic procedures. Rigidity was present in $82.8 \%$ patients in open procedure and $88.5 \%$ in laparoscopic procedure whereas absent in $17.14 \%$ in open and $11.4 \%$ in laparoscopic. The normal findings of the pathology report were seen in $25.7 \%$ in laparoscopic and $11.4 \%$ in open procedures. The abnormal report of the pathology was more seen in open i.e. in $88.57 \%$ than $74.2 \%$ in laparoscopic procedure. (Table no. 5).

In Table no. 6 and 7, it is found that the differential count with shift to left was most commonly present in $91.4 \%$ of the patients in open appendectomy than laparoscopic in $82.8 \%$ of the patients. The pain score was reduced in laparoscopic which is $3.4 \pm 1.8$ and in open $4.2 \pm 1.4$. This difference is found to be statistically significant at $p$ value of 0.05 . The duration of analgesics was also reduced in laparoscopic with mean value of $4.81 \pm 3.6$ and $10.32 \pm 4.2$ and this difference is found to be statistically significant at $p$ value of 0.05 .

Graph no. 1 shows that the duration of surgery (about 3160 minutes) was seen in maximum number of patients in open appendectomy shown with the help of blue bars than laparoscopic appendectomy with the help of red bars. Graph no. 2 shows the most common post-operative complications was vomiting followed by wound infection which was more seen in open than laparoscopic procedure. Graph no. 3 shows that the maximum number of patients were recovered in 13-16 days with the help of open appendectomy whereas in laparoscopic about 6-8 days were taken by maximum number of patients. Graph no. 4 shows the duration of hospital stay of about 4 days after surgery was seen in maximum number of patients with open appendectomy and only 2 days with laparoscopic procedure.

\section{DISCUSSION}

Several studies have shown that laparoscopic appendectomy is safe and results in a faster return to normal activities with fewer wound complications and these findings are in consistent with the present findings. Length of hospital stay is an important factor that directly influences the economy and the well-being of the patient. It was found in the present study that hospital stay was reduced in with the procedure of laparoscopic than open, leading to earlier feeding and discharge from hospital. This finding is in agreement with the various studies which revealed significantly decreased stay in the hospital for the laparoscopic approach. ${ }^{11,12,13}$

Pain was assessed post-operatively subjectively with the help of visual analogue scale and objectively through the tabulation of use of the analgesics. In this present study, parenteral and oral analgesic requirements were less in the laparoscopic group i.e. $4.81 \pm 3.6$ and $10.32 \pm 4.2$ in open group and this difference was found to be statistically significant difference at $\mathrm{p}<0.05$ in agreement with many other studies that reported less pain in the laparoscopic group.

In this study, the days for recovery after surgery were found to be more in open group i.e. within 13-16 days and 6-8 days in laparoscopic group. The findings of this study results are in agreement with the study by Hellberg et al and also other randomized clinical trials and meta-analysis. The low mortality rates reported in previous research $(0.05 \%$ and $0.3 \%$ rate in laparoscopic and open groups indicated that appendectomy, especially in absence of complicated disease, is a safe procedure regardless of the technique used. ${ }^{14,15,16}$

Wound infection is usually seen among complicated appendicitis but necessarily does not represent a serious complication but has a strong impact on the patient's time and quality of life. It was more in open group than laparoscopic group. The presence of vomiting, fever and abdominal abscess was seen in open group post-operatively. The similar studies done showed the incidence of emesis lesser in laparoscopic group. ${ }^{17}$

In the current study, pain score was $10.32 \pm 4.2$ in open and $4.81 \pm 3.6$ in laparoscopic which was due to longer incision stretch of muscles and wound infection and this was found to be statistically significant at $p$ value 0.05 . These findings are in concordance with the studies done by many authors. Although classic open appendectomy is simple and effective, it has some drawbacks including wound sepsis, delayed recovery, and the possibility of unnecessary appendectomies. ${ }^{18}$ In this study, laparoscopic appendectomy significantly improved the postoperative wound infection rate which is in concordance with the study done by M. Marzouk et al where there was no wound infection in the laparoscopic group, whereas in open group the infection rate was $7.6 \%$. This is because with laparoscopic approach, the inflamed appendix was dissected without direct contact with the trocar wounds. ${ }^{19}$

The complete removal of the appendix was done within the trocar sheath, and there was no direct contact with the port opening. When the appendix was too big to pass through the trocar sheath, it was removed in a plastic bag. In the case of a perforated appendix, the infected fluid was aspirated completely in the laparoscopic approach and did not soil the port sites. Also, in laparoscopic operations, we do not close the abdominal sheath in trocars up to $10 \mathrm{~mm}$ in size. This is in contrast to open surgery, in which sutures of the wound and collection of haematoma might be a media for infection. ${ }^{20}$

\section{CONCLUSION}

Laparoscopic appendectomy is safe and effective procedure 
than the open procedure. It significantly reduces the rate of postoperative wound infection, as compared with open surgery.

\section{REFERENCES}

1. Chiarugi M, Buccianti P, Celona G, Decanini L, Martino MC, Goletti O et al. Laparoscopic compared with open appendectomy for acute appendicitis: a prospective study. Eur J Surg 1996; 162(2): 385-390.

2. Garbutt JM, Soper NJ, Shannon W, Botero A, Littenberg B. Meta-analysis of randomized controlled trials comparing laparoscopic and open appendectomy. Surg Laparosc Endosc. 1999; 9(4):17-26.

3. Akshatha Manjunath, Aparajita Mookherjee. Laparoscopic versus open appendectomy: An analysis of the surgical outcomes and cost efficiency in a tertiary care medical college hospital. International Journal of Contemporary Medical Research 2016; 3(6):16961700 .

4. Di Saverio S. Emergency laparoscopy: a new emerging discipline for treating abdominal emergencies attempting to minimize costs and invasiveness and maximize outcomes and patients' comfort. J Trauma Acute Care Surg. 2014; 77(1):338-50.

5. Hansen JB, Smithers MB, Schache D, Wall DR, Miller BJ, Menzies BL. Laparoscopic versus open appendectomy: prospective randomized trial. World J Surg 1996; 20(5): 17-21.

6. Klingler A, Henle KP, Beller S, Rechner J, Zerz A, Wetscher GJ. Laparoscopic appendectomy does not change the incidence of postoperative infectious complications. Am J Surg 175(3): 232-35.

7. Kurtz RJ, Heimann TM. Comparison of open and laparoscopic treatment of acute appendicitis. Am J Surg. 2001; 182(6):211-4.

8. Wullstein C, Barkhausen S, Gross E. Results of laparoscopic vs. conventional appendectomy in complicated appendicitis. Dis Colon Rectum. 2001; 44(1):1700-5.

9. Ravichandran Kailasam Subramaniam. Comparative analysis of clinical outcomes of open appendectomy and laparoscopic appendectomy. International Journal of Contemporary Medical Research 2018; 5(1):18-20.

10. Grosso G, Biondi A, Marventano S, Mistretta A, Calabrese G,BasileF.Major postoperative complications and survival for colon cancer elderly patients. BMC Surg. 2012; 12 Suppl 1:S20.

11. Katkhouda N, Mason RJ, Towfigh S, Gevorgyan A, Essani R. Laparoscopic versus open appendectomy: a prospective randomized double-blind study. Ann Surg. 2005; 242(4):439-48.

12. Ignacio RC, Burke R, Spencer D, Bissell C, Dorsainvil C, Lucha PA. Laparoscopic versus open appendectomy: what is the real difference? Results of a prospective randomized double-blinded trial. Surg Endosc. 2004; 18(3):334-7.

13. Wei B, Qi CL, Chen TF, Zheng ZH, Huang JL, Hu BG, Wei HB. Laparoscopic versus open appendectomy for acute appendicitis: a meta-analysis. Surg Endosc. 2011; 25(3):1199-208.

14. Jaschinski T, Mosch C, Eikermann M, Neugebauer EA.
Laparoscopic versus open appendectomy in patients with suspected appendicitis: a systematic review of meta-analyses of randomised controlled trials. BMC Gastroenterol. 2015; 15(5):48.

15. Chung RS, Rowland DY, Li P, Diaz J. A metaanalysis of randomized controlled trials of laparoscopic versus conventional appendectomy. Am J Surg. 1999; 177(1):250-6.

16. Hellberg A, Rudberg C, Kullmann E, et al. Prospective randomized multicentre study of laparoscopic versus open appendectomy. Br J Surg. 1999; 86(4):48-53.

17. Hart R, Rajgopal C, Plewes A, Sweeney J, Davies W, Gray D, Taylor B. Laparoscopic versus open appendectomy: a prospective randomized trial of 81 patients. Can J Surg. 1996; 39(2):457-62.

18. Golub R, Siddiqui F, Pohl D. Laparoscopic versus open appendectomy: a meta-analysis. J Am Coll Surg. 1998; 186(5):545-53.

19. Marzouk M, Khater M, Elsadek M, Abdelmoghny A. Laparoscopic versus open appendectomy: a prospective comparative study of 227 patients. Surg Endosc. 2003; 17(8):72-14.

20. Olmi S, Magnone S, Bertolini A, Croce E. Laparoscopic versus open appendectomy in acute appendicitis: a randomized prospective study. Surg Endosc. 2005; 19(1):1193-5.

\section{Source of Support: Nil; Conflict of Interest: None}

Submitted: 16-05-2019; Accepted: 15-06-2019; Published online: 15-07-2019 